\title{
Paclitaxel Poliglumex
}

National Cancer Institute

\section{Source}

National Cancer Institute. Paclitaxel Polig/umex. NCI Thesaurus. Code C1795.

The agent paclitaxel linked to a biodegradable, water-soluble polyg lutamate polymer with antineoplastic properties. The polyglutamate residue increases the water solubility of paclitaxel and allows delivery of higher doses than those achievable with paclitaxel alone. Paclitaxel promotes microtubule assembly and prevents microtubule depolymerization, thus interfering with normal mitosis. 